\title{
Assessment of Psychological Distress among the General Public in Saudi Arabia during the Coronavirus Disease-19 Pandemic
}

\author{
Mona Almanasef* D, Dalia Almaghaslah (D) \\ Department of Clinical Pharmacy, College of Pharmacy, King Khalid University, Abha, Saudi Arabia
}

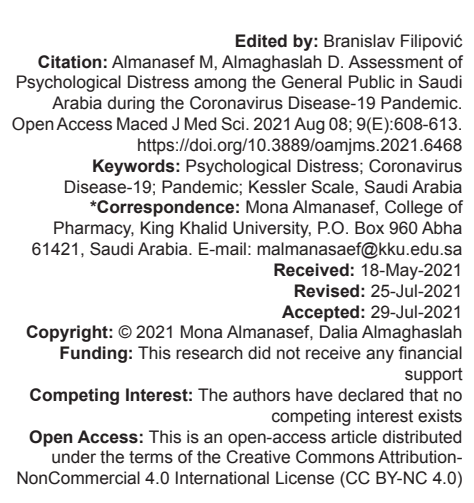

Introduction

The WHO declared the 2019 coronavirus disease (COVID-19) outbreak to be a pandemic on March 1, 2020, following the rapid spread worldwide of the novel virus [1].

Governments around the world issued preventative measures to control the pandemic [2]. The Saudi government started implementing similar emergency precautionary policies as the outbreak continued to evolve. Those policies included social distancing, for example, the lockdown of some cities, suspension of the operations of many government authorities, banning of social gatherings in public places, the establishment of national quarantine for individuals, suspension of the operations of all shopping malls and local markets, as well as suspension of both domestic and international flights. The land borders between the country and all neighboring nations were restricted to commercial traffic only. Other management policies affected Islamic practice, for example, prayers in mosques, which were prohibited, as were visiting the religious sites in Medina and Mecca, and performing pilgrimages, that is, Hajj and Umrah [2].
The Ministry of Education announced the suspension of in-class teaching and learning and the temporary closure of all educational institutions around the Kingdom [2].

By June 21, 2020, all curfews were lifted through a three-phase program, except for social distancing and mask wearing throughout the country.

COVID-19 and its preventative measures disrupted people's day-to-day lives and jobs and consequently had an impact on their health and wellbeing. Studies have revealed high levels of depression, anxiety, and sleep disorders [3].

Psychological distress during the COVID19 pandemic has been evaluated on a national level in several countries. A nationwide survey in China revealed that participants felt isolated due to the strict quarantine and approximately one-third of participants had other psychological issues, such as panic disorder, anxiety, and depression [3]. A nationwide Italian online survey concluded that for females, negative affect and detachment were among the factors that resulted in higher levels of depression, anxiety, and stress. Being previously diagnosed with a medical condition or being exposed to stressful experiences was found 
to be associated with higher levels of depression and anxiety [4]. In Saudi Arabia, a study of the general public revealed moderate-to-severe depression, anxiety, and stress as effects of the outbreak among one-third of participants [5].

The psychological impact of the pandemic was measured by various tools. Some studies developed a survey, such as those of Qiu et al. (2020) and Mazza et al. (2020). Others, including Alkhamees et al. (2020), used validated tools such as the Impact of Event Scale-Revised and the Depression, Anxiety, and Stress Scale-21). Ramasubramanian et al. (2020) used the COVID-19 Peritraumatic Distress Index [3], [4], [5], [6].

A nationwide study in Turkey adapted and validated the fear of COVID-19 scale on the Turkish population [7]. An Arabic version of the fear of COVID19 tool was adapted and validated by a group of researchers in Saudi Arabia among Saudi nationals [8].

The main aim of our study was to determine the prevalence of psychological distress among the general public during COVID-19 pandemic. In addition, it aimed to determine the characteristics of a highly susceptible population.

\section{Methods}

\section{Study design}

This study used a prospective web-based cross-sectional design.

\section{Population and setting}

The study was conducted to assess psychological distress among the general Saudi population. The online data collection took place between July 1, 2020, and July 15, 2020, after the COVID-19 pandemic, curfew restrictions had been eased. According to the Saudi General Authority for Statistics, the total population was $34,218,169$ in mid-2019.

\section{Sample size and sampling procedure}

The sample size was calculated using the Raosoft sample size calculator. Based on the total number of the population $(34,218,169)$, and with a $95 \%$ confidence interval, the minimum sample size was 385. The online questionnaire was designed using Google Forms and was distributed through social media applications, that is, WhatsApp and Twitter. The invitation letter was sent through WhatsApp groups and was posted on the researchers' Twitter pages. The invitation letter contained the title and purpose of the study and the required time for completing the survey. Participants were encouraged to distribute the questionnaire further, through their social networks.

\section{Data collection tool}

The questionnaire consisted of three domains: Demographics/background information, health status and previous contact history, and the Kessler psychological distress scale (K10) [9], [10]. The first two sections were developed by the research team, while the third section used a validated English version of the $\mathrm{K} 10$ [9], [10]. Initially, the questionnaire was prepared in the English language and then translated into the Arabic language. Language validity was undertaken by retranslating the Arabic version of the questionnaire into English, to ensure that the original meaning of the questions was preserved (back translation). The authors, who are bilingual speakers of both English and Arabic, conducted the back translation. An Arabic version of the Kessler psychological distress scale was added to the Arabic version of the questionnaire after obtaining the authors' permission [11]. The questionnaire was distributed in two languages, that is, English and Arabic

\section{Ethical approval}

The Ethical Committee of Scientific Research at King Khalid University approved the research, ECM\# 2020-9110. Respondents were asked for their consent before participation in the study.

\section{Statistical analysis}

An Excel sheet was automatically generated from the online system, Google Forms, permitting the conducting of statistical analyses (automatic data entry), and was analyzed using the Statistical Package for the Social Sciences version 25.0 for Mac. The results were described in terms of frequencies and percentages. Analysis of variance was used to explore the differences in psychological distress rating among the different sociodemographic categories of the study participants. The level of significance was set at an alpha level equal to 0.05 for all analyses.

\section{Results}

A total of 1058 people agreed to participate in the study and completed the questionnaire. About $40.4 \%(n=427)$ of them were male and $59.6 \%(n=631)$ were female. The majority of the participants $(80.2 \%)$ were between 18 and 45 years of age, $17.5 \%$ were in 
the age category 46-60 years, and a small minority $(2.3 \%)$ were 61 years or older. About two-thirds (66.1\%) of the participants were married, $30.2 \%$ were single, and the remaining $3.8 \%$ were divorced or widowed. The demographic information of the participants is reported in Table 1.

Table 1: Comparison of the mean psychological distress scores in relation to the participants' sociodemographic characteristics $(n=1058)$

\begin{tabular}{|c|c|c|c|}
\hline Characteristics & $\mathrm{n}(\%)$ & Mean K10 score (SD) & p value* \\
\hline Gender & & & 0 \\
\hline Male & $427(40.4)$ & $21.38(8.31)$ & \\
\hline Female & $631(59.6)$ & $23.73(8.73)$ & \\
\hline Age category & & & 0 \\
\hline $18-30$ & $394(37.2)$ & $25.63(8.88)$ & \\
\hline $31-45$ & $455(43)$ & $22.03(8.28)$ & \\
\hline $46-60$ & $185(17.5)$ & $19.67(7.16)$ & \\
\hline 61 and older & $24(2.3)$ & $14.25(3.63)$ & \\
\hline Marital status & & & 0 \\
\hline Single & $319(30.2)$ & $26.03(8.81)$ & \\
\hline Married & $699(66.1)$ & $21.39(8.18)$ & \\
\hline Divorced & $32(3)$ & $21.44(8.16)$ & \\
\hline Widowed & $8(0.8)$ & $20.50(9.13)$ & \\
\hline Qualification & & & 0 \\
\hline Less than high school & $48(4.5)$ & $21.94(10.14)$ & \\
\hline High school & $256(24.2)$ & $24.82(8.93)$ & \\
\hline Diploma & $150(14.2)$ & $23.08(9.00)$ & \\
\hline Bachelor's degree & $510(48.2)$ & $22.26(8.15)$ & \\
\hline Master's degree & $42(4)$ & $19.60(8.37)$ & \\
\hline Doctorate & $52(4.9)$ & $20.33(7.50)$ & \\
\hline Employment status & & & 0 \\
\hline Employed (government sector) & $348(32.9)$ & $21.49(8.20)$ & \\
\hline Employed (private sector) & $201(19)$ & $21.52(8.48)$ & \\
\hline Unemployed & $78(7.4)$ & $26.01(9.25)$ & \\
\hline Student & $192(18.1)$ & $26.91(8.35)$ & \\
\hline Self-employed & $23(2.2)$ & $23.04(8.82)$ & \\
\hline Housewife & $140(13.2)$ & $22.74(8.33)$ & \\
\hline Retired & $76(7.2)$ & $18.33(6.73)$ & \\
\hline $\begin{array}{l}\text { Access to a garden or a private } \\
\text { outdoor space }\end{array}$ & & & 0.029 \\
\hline Yes & $594(56.1)$ & $22.15(8.18)$ & \\
\hline No & $464(43.9)$ & $23.59(9.13)$ & \\
\hline Presence of caring responsibilities & & & 0 \\
\hline Yes & $422(39.9)$ & $23.98(8.74)$ & \\
\hline No & $636(60.1)$ & $21.99(8.48)$ & \\
\hline Smoking & & & 0.453 \\
\hline Yes & $195(18.4)$ & $22.37(8.54)$ & \\
\hline No & $863(81.6)$ & $22.87(8.66)$ & \\
\hline Frontline worker/volunteer in the & & & 0.777 \\
\hline fight against COVID-19 & & & \\
\hline Yes & $99(9.4)$ & $23.07(9.18)$ & \\
\hline No & $959(90.6)$ & $22.75(8.58)$ & \\
\hline General health status & & & 0 \\
\hline Excellent & $442(41.8)$ & $21.48(8.48)$ & \\
\hline Very good & $411(38.8)$ & $22.93(8.02)$ & \\
\hline Good & $161(15.2)$ & $24.04(8.93)$ & \\
\hline Fair & $35(3.3)$ & $28.83(9.96)$ & \\
\hline Poor & $9(0.9)$ & $33.78(12.31)$ & \\
\hline
\end{tabular}

A total of $29 \%(n=307)$ of the respondents were in the moderate distress category, somewhat more than a quarter $(26.4 \%)$ had high distress, and about $44 \%$ of the participants were equally divided between the low and very high distress categories. Thus, about $48.6 \%(n=514)$ of the study respondents were psychologically distressed, that is, either in the high or very high distress category.

Female participants reported significantly higher ratings of psychological distress $(M=23.73$, SD $=8.73)$ than male participants $(M=21.38, S D=8.31)$, $p<0.05$. The study revealed that psychological distress decreased with age from the 18-30 age category $(M=$ $25.63, S D=8.88)$, and $31-45$ age category $(M=22.03$, $\mathrm{SD}=8.28)$, to the $46-60$ age category $(M=19.67, \mathrm{SD}=$ $7.16)$, and 60 and older age category $(M=14.25, S D=$ 3.63), $p<0.05$. Conversely, the psychological distress score increased as the health status of respondents got poorer, from excellent $(M=21.48, S D=8.48)$, and very $\operatorname{good}(M=22.93, \mathrm{SD}=8.02)$, to $\operatorname{good}(M=24.04, \mathrm{SD}=$ 8.93), fair $(M=28.83, S D=9.96)$, and poor $(M=33.78$, $\mathrm{SD}=12.31), \mathrm{p}<0.05$ (Table 1).

A significantly higher distress rating score was observed among those whose marital status was single $(M=26.03, S D=8.81), p<0.05$. Likewise, students scored the highest distress score $(M=26.91, \mathrm{SD}=8.35)$ among the different employment status categories followed by the unemployed $(M=26.01$, $S D=9.25)$ and then the self-employed participants $(M=23.04$, $S D=8.82), p<0.05$. Participants whose qualification at the time of study was high school showed a higher distress score rating $(M=24.82, S D=8.93), p<0.05$.

No significant differences in psychological distress were observed between smokers $(M=22.37$, $\mathrm{SD}=8.54)$ and non-smokers $(M=22.87, \mathrm{SD}=8.66)$, $p=0.453$, and frontline workers/volunteers in the fight against COVID-19 $(M=23.07, S D=9.18)$ and others who were not involved $(M=22.75, S D=8.58)$, $\mathrm{p}=0.777$.

The psychological distress score for the participants who indicated having no access to a garden or a private outdoor space in their residential facility was significantly higher $(M=23.59, \mathrm{SD}=9.13)$ than those who had access $(M=22.15, \mathrm{SD}=8.18), \mathrm{p}<0.05$. Similarly, participants who had caring responsibilities for example, caring for children or the elderly - showed a significantly higher distress rating $(M=23.98, S D=8.74)$ than their counterparts $(M=21.99, S D=8.48), p<0.05$.

Participants who, at the time of study, had been in close or indirect contact with an individual with confirmed infection with COVID-19 in the past 14 days showed significantly higher distress scores $(M=33.64$, $S D=12.11 ; M=25.50, S D=9.02$, respectively) compared to those who had not $(M=22.67, \mathrm{SD}=8.53 ; M=22.68$, $\mathrm{SD}=8.61$, respectively), $p<0.05$. However, no significant differences were observed between the individuals who had been in contact with suspected COVID-19 cases or infected materials $(M=25.45, S D=10.48)$ and those who had not $(M=22.68, S D=8.54), p=0.072$. Likewise, there were no significant differences in psychological distress between respondents who had tested positive for COVID-19 in the past 14 days $(M=28.07$, $\mathrm{SD}=14.78)$ and those who had not $(M=22.71$, $\mathrm{SD}=8.53), \mathrm{p}=0.118$ (Table 2).

Table 2: Comparison of the mean psychological distress score in relation to the participants' history of COVID-19 $(n=1058)$

\begin{tabular}{llll}
\hline Characteristics & $\mathrm{n}(\%)$ & Mean K10 score (SD) & p value* \\
\hline \multicolumn{2}{l}{ Tested positive for COVID-19 } & & \\
Yes & $14(1.3)$ & $28.07(14.78)$ & 0.118 \\
No & $1044(98.7)$ & $22.71(8.53)$ & \\
Been in close contact with a COVID-19 case & & \\
Yes & $11(1)$ & $33.64(12.11)$ & 0.001 \\
No & $1047(99)$ & $22.67(8.53)$ & \\
Been in indirect contact with a COVID-19 case & & \\
Yes & $40(3.8)$ & $25.50(9.02)$ & 0.032 \\
No & $1018(96.2)$ & $22.68(8.61)$ & \\
Been in contact with suspected COVID-19 cases or infected materials & \\
Yes & $42(4)$ & $25.45(10.48)$ & 0.072 \\
No & $1016(96)$ & $22.68(8.54)$ & \\
\hline *ANOVA test, $p<0.05$ is considered statistically significant. & \\
\hline
\end{tabular}




\section{Discussion}

The main aim of this study was to determine the prevalence of psychological distress among the general public during the COVID-19 pandemic. In addition, it aimed to determine the characteristics of a highly susceptible population. The current study revealed that just less than half of the Saudi population experienced high or very high psychological distress in July 2020, around 4 months after the declaration of the COVID-19 pandemic. An earlier piece of research that evaluated the psychological impact of the pandemic on the general Saudi population showed that in April 2020, around $13.7 \%$ of the population had severe or extremely severe stress, $13.9 \%$ had severe or extremely severe anxiety, and $16.4 \%$ had severe or extremely severe depression [5]. The higher prevalence of psychological distress in our study could be attributed to the fact that the number of COVID-19 cases in July is higher than those reported during the $2^{\text {nd }}$ month of the pandemic.

The findings of the current study are consistent with those of other studies and suggest that younger age, female gender, and poor self-reported health status are linked to poorer mental health during the COVID-19 pandemic [5], [12]. Being female is a well-established risk factor for psychological distress [13]. The previous research suggests that the resilience and ability to cope among older adults are greater than among the younger population [14]. Other research studies argue that the younger population have greater access to information about the current pandemic through digital platforms, and this, in turn, could contribute negatively to their stress and anxiety [4]. A higher level of distress among those with poor self-reported health status could be explained by the fact that they might worry about contracting the virus and developing serious complications.

The present study also found that higher levels of distress were reported among single participants. Earlier studies showed that being married protects against psychological burden and distress [15]. Our study revealed that among the different employment status categories, the highest distress scores were observed in the students followed by the unemployed and then self-employed participants. The student population belong to the young age group which, as previously mentioned, is found to be less resilient than older adults. This could also be explained by the fact that the teaching in Saudi Arabia at the time of the conducting of the study had shifted fully to digital/virtual teaching, with the suspension of all faceto-face sessions. A previous study that evaluated undergraduate students' perceptions of online learning suggested that Saudi students prefer the traditional face-to-face teaching as they are not used to online learning [16]. The higher level of psychological distress observed among the unemployed and the self-employed could be attributed to the global economic crises and the growing uncertainty resulting from the COVID-19 pandemic [17]. The previous evidence indicates that employment contributes to personal identity, purpose in life, as well as acting as a source of self-esteem [17].

Individuals with caring responsibilities - for example, caring for an ill person or children - were found in the current study to experience higher levels of psychological distress. This finding is in agreement with George et al. (2020) who showed that individuals with caring responsibilities, either full time or part time, experience greater psychological distress than noncarers [18]. Those caring for children, especially fulltime workers, could be burdened by home schooling and the difficulty of finding an alternative care provider for their offspring, as schools and nurseries have been shut.

The current study found that higher psychological distress was observed among those who have no access to a garden or a private outdoor space in their residential facility. An earlier piece of research conducted in Spain to evaluate the health-related factors of psychological distress during the COVID19 pandemic indicated that living in a house with an outdoor space serves as a protective factor against psychological distress [19].

Higher levels of psychological distress were observed among individuals who had been in close or indirect contact with an individual with confirmed COVID-19 infection. This might be attributed to the psychological burden of the uncertainty and the possibility of being infected with the COVID-19 virus.

\section{Limitations}

The findings in the current study are subject to a number of limitations. First, causality cannot be established by the use of a cross-sectional design. Second, the use of an online questionnaire limits the recruitment process to individuals who are digitally literate. Thus, the views of digitally illiterate individuals, or those who have no or limited access to the digital sphere, are underrepresented in the current report.

\section{Conclusion}

The current study provides a snapshot evaluation of the psychological distress among the adult Saudi community 4 months after the declaration of the COVID-19 pandemic. It reveals that psychological distress is highly prevalent among the general public in Saudi Arabia during COVID-19 pandemic. Significantly 
higher ratings of psychological distress were observed among female participants, the younger adults, those who self-reported poor health status, single persons, students, and individuals with caring responsibilities, and those who have no access to a private outdoor space, and also among those who have been in close or indirect contact with an individual with confirmed COVID-19 infection. The Saudi government and the health authorities should pay special attention to the highly susceptible sections of the population and implement effective strategies to preserve and improve the mental health and well-being of these individuals.

\section{Acknowledgments}

The authors would like to thank the Scientific Deanship at King Khalid University for their administrative and technical support.

\section{References}

1. Almaghaslah D, Kandasamy G, Almanasef M, Vasudevan R, Chandramohan S. Review on the coronavirus disease (COVID19) pandemic: Its outbreak and current status. Int J Clin Pract. 2020;74(11):e13637. https://doi.org/10.1111/ijcp.13637 PMid:32750190

2. Almaghaslah D, Alsayari A. The effects of the 2019 novel coronavirus disease (COVID-19) outbreak on academic staff members: A case study of a pharmacy school in Saudi Arabia. Risk Manag Healthc Policy. 2020;13:795-802. https://doi. org/10.2147/rmhp.s260918

PMid:32765134

3. Qiu J, Shen B, Zhao M, Wang Z, Xie B, Xu Y. A nationwide survey of psychological distress among Chinese people in the COVID-19 epidemic: Implications and policy recommendations. Gen Psychiatry. 2020;33(2):e100213. https://doi.org/10.1136/ gpsych-2020-100213

PMid:32215365

4. Mazza C, Ricci E, Biondi S, Colasanti M, Ferracuti S, Napoli C, et al. A nationwide survey of psychological distress among Italian people during the COVID-19 pandemic: Immediate psychological responses and associated factors. Int $\mathrm{J}$ Environ Res Public Health. 2020;17(9):3165. https://doi.org/10.3390/ ijerph17093165

PMid:32370116

5. Alkhamees AA, Alrashed SA, Alzunaydi AA, Almohimeed AS, Aljohani MS. The psychological impact of COVID-19 pandemic on the general population of Saudi Arabia. Compr Psychiatry. 2020;102:152192. https://doi.org/10.1016/j. comppsych.2020.152192

PMid:32688022

6. Ramasubramanian V, Mohandoss AA, Rajendhiran G, Pandian PR, Ramasubramanian C. Statewide survey of psychological distress among people of Tamil Nadu in the COVID-19 pandemic. Indian J Psychol Med. 2020;42(4):368-73. https://doi.org/10.1177/0253717620935581

PMid:33398225

7. Satici B, Gocet-Tekin E, Deniz ME, Satici SA. Adaptation of the fear of COVID-19 scale: Its association with psychological distress and life satisfaction in Turkey. Int $\mathrm{J}$ Ment Health Addict 2020;2020:141. https://doi.org/10.1007/ s11469-020-00294-0

8. Alyami M, Henning M, Krägeloh CU, Alyami H. Psychometric evaluation of the arabic version of the fear of COVID-19 scale. Int J Ment Health Addict. 2020;2020:1-14. https://doi. org/10.1007/s11469-020-00316-x PMid:32427217

9. Kessler RC, Barker PR, Colpe LJ, Epstein JF, Gfroerer JC, Hiripi $E$, et al. Screening for serious mental illness in the general population. Arch Gen Psychiatry. 2003;60(2):184-9. https://doi. org/10.1001/archpsyc.60.2.184

PMid:12578436

10. Kessler RC, Andrews G, Colpe LJ, Hiripi E, Mroczek DK, Normand SL, et al. Short screening scales to monitor population prevalences and trends in non-specific psychological distress. Psychol Med. 2002;32(6):959-76. https://doi.org/10.1017/ s0033291702006074 PMid:12214795

11. Easton SD, Safadi NS, Wang Y, Hasson RG. The Kessler psychological distress scale: Translation and validation of an Arabic version. Health Qual Life Outcomes. 2017;15(1):215. https://doi.org/10.1186/s12955-017-0783-9 PMid:29078774

12. Dawel $A$, Shou $Y$, Smithson $M$, Cherbuin $N$, Banfield $M$, Calear AL, et al. The effect of COVID-19 on mental health and wellbeing in a representative sample of Australian adults. Front Psychiatry. 2020;11:579985. https://doi.org/10.3389/ fpsyt.2020.579985 PMid:33132940

13. Ritsner M, Ponizovsky A, Nechamkin Y, Modai I. Gender differences in psychosocial risk factors for psychological distress among immigrants. Compr Psychiatry. 2001:42(2):15160. https://doi.org/10.1053/comp.2001.19750 PMid:11244152

14. MacLeod S, Musich S, Hawkins K, Alsgaard K, Wicker ER. The impact of resilience among older adults. Geriatr Nurs (Minneap). 2016;37(4):266-72. https://doi.org/10.1016/j. gerinurse.2016.02.014 PMid:27055911

15. Rodríguez-Rey $\mathrm{R}$, Garrido-Hernansaiz $\mathrm{H}$, Collado $\mathrm{S}$ Psychological impact and associated factors during the initial stage of the coronavirus (COVID-19) pandemic among the general population in Spain. Front Psychol. 2020;11:1540. https://doi.org/10.3389/fpsyg.2020.01540 PMid:32655463

16. Almaghaslah D, Ghazwani M, Alsayari A, Khaled A. Pharmacy students' perceptions towards online learning in a Saudi pharmacy school. Saudi Pharm J. 2018;26(5):617-21. https:// doi.org/10.1016/j.jsps.2018.03.001 PMid:29991906

17. Achdut N, Refaeli T. Unemployment and psychological distress among young people during the COVID-19 pandemic: Psychological resources and risk factors. Int J Environ Res Public Health. 2020;17(19):7163. https://doi.org/10.3390/ijerph17197163 PMid:33007892

18. George ES, Kecmanovic M, Meade T, Kolt GS. Psychological distress among carers and the moderating effects of social support. BMC Psychiatry. 2020;2020:154. https://doi. org/10.1186/s12888-020-02571-7 
19. Ruiz-Frutos $C$, Ortega-Moreno $M$, Allande-Cussó R, DomínguezSalas S, Dias A, Gómez-Salgado J. Health-related factors of psychological distress during the COVID-19 pandemic among non-health workers in Spain. Saf Sci. 2021;133:104996. https:// doi.org/10.1016/j.ssci.2020.104996

PMid:32952305 